\title{
Impact of the variations in potential glycosylation sites of the hemagglutinin of H9N2 influenza virus
}

\author{
Qianqian Peng ${ }^{1,2,6} \cdot$ Rui Zhu ${ }^{1,2,6} \cdot$ Xiaobo Wang $^{1,2,6} \cdot$ Huoying Shi ${ }^{1,2,3,4,6} \cdot$ Matthew Bellefleur $^{5} \cdot$ Shifeng Wang ${ }^{5}$. \\ Xiufan Liu ${ }^{1,2,6}$
}

Received: 20 July 2018 / Accepted: 10 December 2018 / Published online: 29 December 2018

(c) The Author(s) 2018

\begin{abstract}
Variations in the potential glycosylation sites were observed in hemagglutinin (HA) sequences of H9N2 avian influenza virus isolated in China, deposited in the Influenza Virus Resource of NCBI before 2017, which showed a deleted glycosylation site at amino acid residue 218, and an introduced glycosylation site at amino acid residue 313 . Based on the variations in the glycosylation sites at these amino acids, H9N2 avian influenza viruses could be divided into three categories. Firstly, most of the H9N2 influenza viruses were $218 \mathrm{G}^{+}$viruses; less $313 \mathrm{G}^{+}$viruses were isolated between 1997 and 2004. Secondly, the occurrence of the $218 \mathrm{G}^{+} / 313 \mathrm{G}^{+}$viruses increased, while the $218 \mathrm{G}^{+} / 313 \mathrm{G}^{-}$viruses decreased from 2005 to 2012 . Thirdly, from 2013 to 2016 , the $218 \mathrm{G}^{-} / 313 \mathrm{G}^{+}$viruses were predominant compared to the $218 \mathrm{G}^{+} / 313 \mathrm{G}^{+}$viruses. Here, based on an $\mathrm{F} / 98$ virus backbone, a $218 \mathrm{G}^{+} / 313 \mathrm{G}^{-}$virus, two reassortment viruses were generated, and named $\mathrm{rF} / \mathrm{HA} 218 \mathrm{G}^{+} / 313 \mathrm{G}^{+}$and $\mathrm{rF} / \mathrm{HA} 218 \mathrm{G}^{+} / 313 \mathrm{G}^{-}$, respectively. HA protein migration demonstrated that the glycosylation sites at amino acid residues 313 and 218 were both functional. The absence of the glycosylation site at amino acid residue 218 and the presence of the glycosylation site at amino acid residue 313 increased antibody binding and moderately prevented the virus from escaping neutralization with homologous antisera. Additionally, compared to the $\mathrm{F} / 98$ virus $\left(218 \mathrm{G}^{+} / 313 \mathrm{G}^{-}\right)$, the viruses $\mathrm{rF} /$ $\mathrm{HA} 218 \mathrm{G}^{+} / 313 \mathrm{G}^{+}$or $\mathrm{rF} / \mathrm{HA} 218 \mathrm{G}^{-} / 313 \mathrm{G}^{+}$showed significantly increased infectivity of MDCK cells, chicken embryo eggs, and trachea and lung tissue of SPF chickens, but did not display differences in airborne spread in chickens or infectivity of mice compared with its parental virus F/98.
\end{abstract}

Keywords H9N2 - Glycosylation sites · Hemagglutinin · Aa residue $218 \cdot$ Aa residue 313

Edited by William Dundon.

$$
\begin{aligned}
& \text { Huoying Shi } \\
& \text { hyshi@yzu.edu.cn } \\
& \text { Shifeng Wang } \\
& \text { shifengwang@ufl.edu } \\
& \text { Qianqian Peng } \\
& \text { 1475287399@qq.com } \\
& \text { Rui Zhu } \\
& \text { rzhu1988@163.com } \\
& \text { Xiaobo Wang } \\
& \text { wangxb@yzu.edu.cn } \\
& \text { Matthew Bellefleur } \\
& \text { mbellefl@ufl.edu } \\
& \text { Xiufan Liu } \\
& \text { xfliu@yzu.edu.cn }
\end{aligned}
$$

1 College of Veterinary Medicine, Yangzhou University, Yangzhou 225009, Jiangsu, China

2 Key Laboratory of Avian Preventive Medicine, Ministry of Education, Yangzhou University, Yangzhou, China

3 Jiangsu Key Laboratory of Preventive Veterinary Medicine, Yangzhou University, Yangzhou, China

4 Key Laboratory of Animal Infectious Diseases, Ministry of Agriculture, Yangzhou University, Yangzhou, China

5 Department of Infectious Diseases and Immunology, College of Veterinary Medicine, University of Florida, Gainesville, FL 32611-0880, USA

6 Jiangsu Co-innovation Center for the Prevention and Control of Important Animal Infectious Diseases and Zoonoses, Yangzhou 225009, China 


\section{Introduction}

The H9N2 avian influenza virus was first detected in the North American turkey in 1966, after which it spread throughout the world, causing huge economic losses in the poultry industry. The antigenic structure of the H9N2 influenza virus has been changing all the time, including changes in N-linked glycosylation (NLG) sites of the hemagglutinin (HA) protein [1]. NLG is a specific posttranslational modification of viral surface glycoproteins, HA and neuraminidase (NA), whereby oligosaccharides are attached through $\mathrm{N}$-glycosidic linkages to the Asn residue of the glycosylation motif Asn-X-Ser/Thr-X, where X may represent any amino acid except proline [2]. NLGs from HA protein play an important role on a further structural and functionality modification of influenza A virus (IAV). Glycosylation is essential for protein folding and maturation through the endoplasmic reticulum (ER) and golgi apparatus [3]. Changes in the number or location of NLG sites in the spherical head of HA protein can affect the biological activity of IAV [4]. NLGs of HA protein regulate the virulence of IAV by adjusting the biological activity of HA in the IAV [5-8]. Furthermore, NLGs allow IAV to evade host antibody recognition [9, 10]. The NLG status of the receptor-binding domain of HA in IAV mediates protective antibody responses against the 1918 and 2009 pandemic H1N1 viruses [11, 12]. Modifying glycosylation sites, especially in the stalk domain, have been explored to broaden the breadth of antibody responses induced by vaccination [13]. HA protein of the IAV is the primary target for neutralizing antibody recognition. NLGs have been shown to shield the antigenic sites in HA and promote the evolution of the virus [1]. Moreover, addition of a NLG was associated with resistance to neutralizing or enhancing growth in vaccinated mice [14]. And, the receptor binding avidity through the addition of NLGs to the HA globular domain was modulated to maintain fitness during antigenic evolution [15].

HA protein of IAV is the major target recognized by neutralizing antibodies and glycans have been proposed to shield antigenic sites on HA, thereby promoting virus survival in the face of widespread vaccination and/or infection $[1,8,16]$. The variations in the glycosylation (abbreviates G) sites at amino acid residues 218 (named $218 \mathrm{G}^{+}$, Asn-Arg-Thr-Phe, NRTF) and 313 (named $313 \mathrm{G}^{+}$, Asn-Cys-Ser-Lys, NCSK) emerged in the process of the evolution of H9N2 avian influenza viruses. There are four phenotype including $218 \mathrm{G}^{+} / 313 \mathrm{G}^{-}, 218 \mathrm{G}^{+} / 313 \mathrm{G}^{+}$, $218 \mathrm{G}^{-} / 313 \mathrm{G}^{+}$, and $218 \mathrm{G}^{-} / 313 \mathrm{G}^{-} .218 \mathrm{G}^{+}$means the glycosylation site at amino acid residues 218; in contrast, $218 \mathrm{G}^{-}$means no glycosylation site at amino acid residues 218 , which are similar to $313 \mathrm{G}$. And we propose the hypotheses that the variations in NLG sites of HA protein in H9N2 influenza virus might affect the biological characteristics of the H9N2 influenza virus. In this study, two reassortment viruses were generated by the reverse genetics system of influenza virus based on the $\mathrm{F} / 98$ virus backbone, a $218 \mathrm{G}^{+} / 313 \mathrm{G}^{-}$virus, and named $\mathrm{rF} /$ $\mathrm{HA} 218 \mathrm{G}^{+} / 313 \mathrm{G}^{+}$and $\mathrm{rF} / \mathrm{HA} 218 \mathrm{G}^{+} / 313 \mathrm{G}^{-}$, respectively. The effect of the variations in NLG sites on the H9N2 influenza virus was explored in antibody binding, and infectivity of embryonated eggs of specific-pathogen-free (SPF), MDCK cells, or SPF chickens.

\section{Materials and methods}

\section{Ethics statement}

All animal experiments were approved by the Jiangsu Administrative Committee for Laboratory Animals (permission number SYXK-SU-2007-0005) and complied with the Jiangsu Laboratory Animal Welfare and Ethics guidelines of the Jiangsu Administrative Committee of Laboratory Animals. All experiments were performed under biosafety level 2 (BSL2). All generated viruses included the variations in the glycosylation sites at amino acid residues 313 and 218, which had been found in nature, and not created artificially.

\section{Virus, cell, and sequence analysis of the HA gene of the H9N2 virus}

The H9N2 virus, A/Chicken/Shanghai/F/98 (H9N2, Ck/ SH/F/98; abbreviated as F/98), was isolated in Shanghai in 1998, stored at $-70{ }^{\circ} \mathrm{C}$ at the Animal Infectious Disease Laboratory, School of Veterinary Medicine, Yangzhou University, and identified by the National Influenza Center as the H9N2 subtype influenza virus [17, 18]. The GenBank accession numbers of the full gene sequence of the F/98 strain are AY253750-AY253756 and AF461532 [17]. Human embryonic kidney cells (293T) and Madin-Darby canine kidney (MDCK) cells, purchased from ATCC (Manassas, VA, USA), were maintained in Dulbecco's modified Eagle's medium (DMEM) (Sigma, St. Louis, MO, USA) supplemented with $10 \%$ fetal calf serum (Hyclone, South Logan, UT, USA) and were incubated at $37{ }^{\circ} \mathrm{C}$ with $5 \% \mathrm{CO}_{2}$.

HA protein sequences of the $\mathrm{H} 9 \mathrm{~N} 2$ avian influenza viruses collected in China from 1998 to 2016, published before 2017 (date to Jan 1, 2017), were downloaded from the Influenza Virus Resource of NCBI (https://www.ncbi.nlm. nih.gov/genomes/FLU/Database/nph-select.cgi?go=datab ase). After collapsing identical sequences, about 1900 HA sequences were available. The variations in potential NLG sites in HA protein were analyzed using DNAstar5.0 software (DNAstar, Madison, WI, USA). 


\section{Cloning and generation of viral strains by reverse genetics}

The primers, synthesized by Sangon Biotech (Shanghai) Co., Ltd. (Shanghai, China), used to amplify the DNA sequence to add the NLG site at amino acid residue 313 or to delete the NLG site at amino acid residue 218 in HA protein of F/98 virus were designed using Primer 5.0 software (Primer-E Ltd., Plymouth, UK), based on the HA gene sequence of the F/98 H9N2 avian influenza virus (primer sequences $\left(5^{\prime}-3^{\prime}\right)$ : HA-F, GTCGACCTCCGAAGT TGGGGGGGAGCAAAAGCAGGCGAATTTCA; HA-R, GGCATTTTGGGCCGCCGGGTTATTAGTAGAAAC AAGGGTGTTTTT; $313 \mathrm{G}^{+}-\mathrm{F}$, TTTGGAAACTGCTCA AAGTATGTTG; $313 \mathrm{G}^{+}$-R, CAACATACTTTGAGCAGT TTCCAAA; $218 \mathrm{G}^{-}$-F, ATATAAATAGAGTCTTCAAAC CAAT; $218 \mathrm{G}^{-}$-R, ATTGGTTTGAAGACTCTATTTATA $\mathrm{T})$. The full-length HA genes containing either the $313 \mathrm{G}^{+}$ mutation or the $218 \mathrm{G}^{-} / 313 \mathrm{G}^{+}$mutations were amplified by PCR, and inserted into the transcriptional/expression vector pHW2000 gifts from Webster RG from St. Jude Children's Research Hospital [19], resulting in the plasmids pHW204-

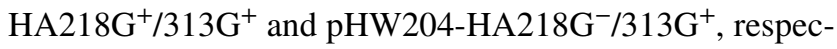
tively. Seven transcription/expression plasmids, including pHW201-PB2, pHW202-PB1, pHW203-PA, pHW205-NP, pHW206-NA, pHW207-M, and pHW208-NS, from the F/98 virus strain, were stocked in our lab at $-70{ }^{\circ} \mathrm{C}$ [18]. A total weight of $2.4 \mathrm{ng}$ of the eight plasmid mixture with a certain weight of $1: 1$ was mixed with $100 \mu \mathrm{L}$ Opti-MEM medium (GIBCO, BRL, Grand Island, USA). Next, $7 \mu \mathrm{L}$ of PolyFect transfection reagent (QIAGEN, Duesseldorf, Germany) was added, and the samples were incubated at room temperature for $10 \mathrm{~min}$ and then added to the $80 \%$ confluent monolayers of $293 \mathrm{~T}$ cell in 24 -well plates. After incubation at $37^{\circ} \mathrm{C}$ with $5 \% \mathrm{CO}_{2}$ for $6 \mathrm{~h}, 2 \mu \mathrm{g} / \mathrm{mL}$ of tosylamide-phenyl-chloromethyl-ketone (TPCK)-trypsin (Sigma, St. Louis, MO, USA) was added to the wells. Thirty hours after transfection, the supernatants were harvested and inoculated into 10-day-old SPF embryonated chicken eggs for virus propagation. The rescued viruses were analyzed with a hemagglutinin assay, and the HA genes from the rescued viruses were sequenced by the Sangon Biotech (Shanghai) Co., Ltd. (Shanghai, China) to confirm the accuracy of the designed mutations.

\section{Hemagglutinin-inhibition (HI) assay}

The HI assay was performed with an initial dilution of 1:10 according to standard methods [20]. The serum of the F/98 H9 avian influenza virus was collected from blood of three SPF chickens in our laboratory. Newcastle disease virus (NDV) and H5 subtype AIV sera were provided by the Animal Infectious Disease Laboratory of Yangzhou University, and 1\% (vol/vol) solution of chicken red blood cells was used to carry out the assay [20]. Sera were treated for $18 \mathrm{~h}$ with RDE (a cholera leachate) (Sigma, St. Louis, MO, USA) to remove nonspecific inhibitors.

\section{Western blotting analyses}

Viruses were propagated in the allantoic cavity of SPF chicken eggs and then purified by $20 \%$ sucrose gradient centrifugation at $30,000 \mathrm{rpm}$ for $3 \mathrm{~h}$. The concentrated virus was re-suspended in phosphate-buffered saline (PBS). Western blotting was performed to analyze the samples. Antisera against the F/98 virus in chicken was used as a primary antibody, and horseradish peroxidaseconjugated rabbit anti-chicken immunoglobulin $\mathrm{G}(\mathrm{IgG})$ (Abcam, Cambridge, MA) was used as a second antibody [21]. Binding was visualized with a chemiluminescent substrate using the kit ECL Plus Western Blotting System (GE Health-care, Chalfont St Giles, UK) according to manufacturer's instructions. The quantitative analysis on movement was conducted using ImageJ program.

\section{Enzyme-linked immunosorbent assays (ELISAs)}

Sucrose gradient-purified viruses were diluted in PBS and added to Nunc-Immuno MaxiSop 96-well plates (Corning, NY, USA) at 16 hemagglutinating units (HAU) per well. After incubation overnight at $4{ }^{\circ} \mathrm{C}$, samples in wells were blocked with PBS-nonfat dry milk. Antisera against the F/98 virus in chicken were then added in serial twofold dilutions with PBS containing $0.05 \%$ Tween-20, and incubated for $3 \mathrm{~h}$ at $37^{\circ} \mathrm{C}$. After washing, goat anti-chicken horseradish peroxidase antibody (Abcam, Cambridge, MA) was added and allowed to incubate for $1.5 \mathrm{~h}$ at $37^{\circ} \mathrm{C}$. After washing, TMB (3,3',5,5'-Tetramethylbenzidine) (Sigma, St. Louis, MO, USA) substrate was added, and the reaction was stopped by adding $\mathrm{H}_{2} \mathrm{SO}_{4}$. Absorbance was recorded at $450 \mathrm{~nm}$ using an automated ELISA plate reader (model EL311SX; Biotek, Winooski, VT) [22].

\section{Determination of the $50 \%$ egg infectious dose $\left(E^{1} D_{50}\right)$}

Virus samples diluted in PBS containing four antibiotics at concentrations of $10^{-4}$ to $10^{-11}$ were inoculated into 10-day-old SPF chicken eggs, respectively. The allantoic fluid of the allantoic cavity of the eggs from 24 to $120 \mathrm{~h}$ post-infection was harvested and analyzed for HA titers. The EID ${ }_{50}$ of the virus was calculated according to the Reed-Muench formula [23]. 


\section{Determination of the $\mathbf{5 0 \%}$ tissue cell infectious dose $\left(\right.$ TCID $\left._{50}\right)$}

The virus was diluted in DMEM without serum to a concentration of $10^{-1}$ to $10^{-11}$ and then added to MDCK cells in 96-well plates, respectively. After incubation at $37{ }^{\circ} \mathrm{C}$ with $5 \% \mathrm{CO}_{2}$ for $1 \mathrm{~h}$, the supernatants were removed. The plates were washed twice with PBS, and then $100 \mu \mathrm{L}$ of DMEM was added to every well. After incubation at $37^{\circ} \mathrm{C}$ with $5 \% \mathrm{CO}_{2}$ for $72 \mathrm{~h}$, the HA titers of the cell supernatants were analyzed. The virus titers were calculated according to the Reed-Muench formula [23].

\section{Chicken experiments}

To evaluate the effect of NLG sites at amino acid residues 313 and 218 on the pathogenicity of the viruses in chickens, 21-day-old White Leghorn SPF chickens, obtained from Laboratory Animal Center of Yangzhou University, were infected intranasally and intratracheally with a dose of $10^{6} \mathrm{EID}_{50}$ of each virus. 3 and 5 days post-infection, the chickens were dissected following euthanasia with $\mathrm{CO}_{2}$, and the trachea and lung tissues were collected and ground into $20 \%(\mathrm{w} / \mathrm{v})$ suspension in $1 \mathrm{~mL}$ PBS. Dilutions of $10^{-1}$ to $10^{-10}$ were inoculated into 10 -day-old SPF chicken eggs. The eggs that died within $24 \mathrm{~h}$ were discarded, and the allantoic fluids in the allantoic cavity of SPF chicken eggs from 24 to $120 \mathrm{~h}$ were harvested and the HA titers were analyzed. The virus titers of the tissues were calculated according to the Reed-Muench formula [23].

\section{Mouse experiments}

As previous reported, the glycosylation in the globular head of HA can affect on the pathogenicity and antigenicity of H5N1 AIVs [24]. Although the parent virus F/98 cannot infect mice $[25,26]$, we wonder whether the glycosylation site changes at amino acid residues 313 and 218 impact the viral phenotype in mice. To evaluate whether the strains with variations of potential NLG sites at amino acid residues 313 and 218 could replicate in mice, 6-weekold female BALB/c mice purchased from the Experimental Animal Center of Yangzhou University were infected intranasally with $10^{6} \mathrm{EID}_{50}$ of each virus in $50 \mu \mathrm{L}$ of PBS. On days 3 and 5 after infection, the mice were dissected following euthanasia, and the trachea and lung tissues of the mice were collected and into $20 \%(w / v)$ suspension in $1 \mathrm{~mL}$ PBS. Dilutions of $10^{-1}$ to $10^{-10}$ were inoculated into 10-day-old SPF chicken eggs. The allantoic fluids in the allantoic cavity of the eggs were harvested from 24 to $120 \mathrm{~h}$, and the HA titers were analyzed.

\section{The spread and immunogenic characteristics of the virus}

To evaluate whether NLG sites at amino acid residues 313 and 218 affect the transmission route of the virus, 27 21-dayold SPF chickens were divided into three groups, labeled as $\mathrm{F} / 98,218 \mathrm{G}^{+} / 313 \mathrm{G}^{+}$, and $218 \mathrm{G}^{-} / 313 \mathrm{G}^{+}$group. Each group was further divided into 3 subgroups with each consisting of three chickens: the inoculated subgroup, the direct-contact subgroup, and the airborne contact subgroup. On the first day post-inoculation (dpi), naive chickens were housed in the same cage with inoculated chickens for the direct-contact subgroup, and naive chickens were placed in a cage directly adjacent to an inoculated subgroup for the airborne contact subgroup, with a distance of $50 \mathrm{~cm}$ between cages. Chickens in the inoculated subgroup of each virus were inoculated orally, intranasally, and intratracheally with $0.2 \mathrm{~mL}$ of a $10^{6} \mathrm{EID}_{50}$ of the virus in PBS. Tracheal and cloacal swabs were obtained from these chickens at 3, 5, 7, and 9 dpi, and the virus of the tracheal and cloacal swabs was titrated in 10-day-old SPF chicken eggs for EID $_{50}$ counts [23].

To identify whether the variations in potential glycosylation site at amino acid residues 313 and 218 resulted in antigenic variation of the H9N2 virus, the cross-protection between $\mathrm{F} / 98$ and $\mathrm{rF} / \mathrm{HA} 218 \mathrm{G}^{+} / 313 \mathrm{G}^{+}$or $\mathrm{rF} /$

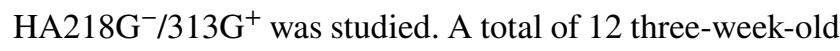
SPF chickens were divided into four groups: the PBS group, the F/98 group, the $\mathrm{rF} / \mathrm{HA} 218 \mathrm{G}^{+} / 313 \mathrm{G}^{+}$group, and the $\mathrm{rF} /$ $\mathrm{HA}_{2} 18 \mathrm{G}^{-} / 313 \mathrm{G}^{+}$group. Each group has three chickens. Chickens in the PBS group were immunized with PBS as a control, and the chickens in the $\mathrm{F} / 98, \mathrm{rF} / \mathrm{HA} 218 \mathrm{G}^{+} / 313 \mathrm{G}^{+}$, and $\mathrm{rF} / \mathrm{HA} 218 \mathrm{G}^{-} / 313 \mathrm{G}^{+}$groups were immunized with the emulsion vaccine of the F/98 strain. At 3 weeks post-inoculation, chickens were bled from the wing vein for sera and challenged intranasally and intratracheally with $10^{6}$ EID $_{50}$ of the indicated virus. Chickens were monitored daily for morbidity and mortality after challenge. At day 3 and 5 postchallenge, tracheal and cloacal swabs from challenged chickens were collected in $1 \mathrm{~mL}$ of PBS containing antibiotics and, following one freeze-thaw cycle, were centrifuged at $3000 \mathrm{rpm}$ for $10 \mathrm{~min}$. Of the resulting supernatant, $0.2 \mathrm{~mL}$ was taken, and inoculated in 10-day-old SPF chicken eggs. Viral shedding in the trachea and cloacal was evaluated via HA titers of the allantoic cavity of SPF chicken eggs at day 5 post-inoculated according to the standard of $\mathrm{HA} \geq 2^{3}$ [27].

\section{Statistics analysis}

Data were presented as the geometric means and standard deviations for all assays. The Mann-Whitney U test (GraphPad Software, Inc., San Diego, CA) was used to evaluate the differences in anti-F/98 serum binding to different viruses. A $P$ value of 0.05 was considered statistically significant. 
Means and SEM from triplicate samples are shown. The data are representative of three independent experiments.

\section{Results}

\section{Analysis potential glycosylation sites of the HA in H9N2 influenza virus and the generation of the mutant viruses}

To investigate the variations in NLG sites at amino acid residues 313 and 218, the HA sequences of the H9N2
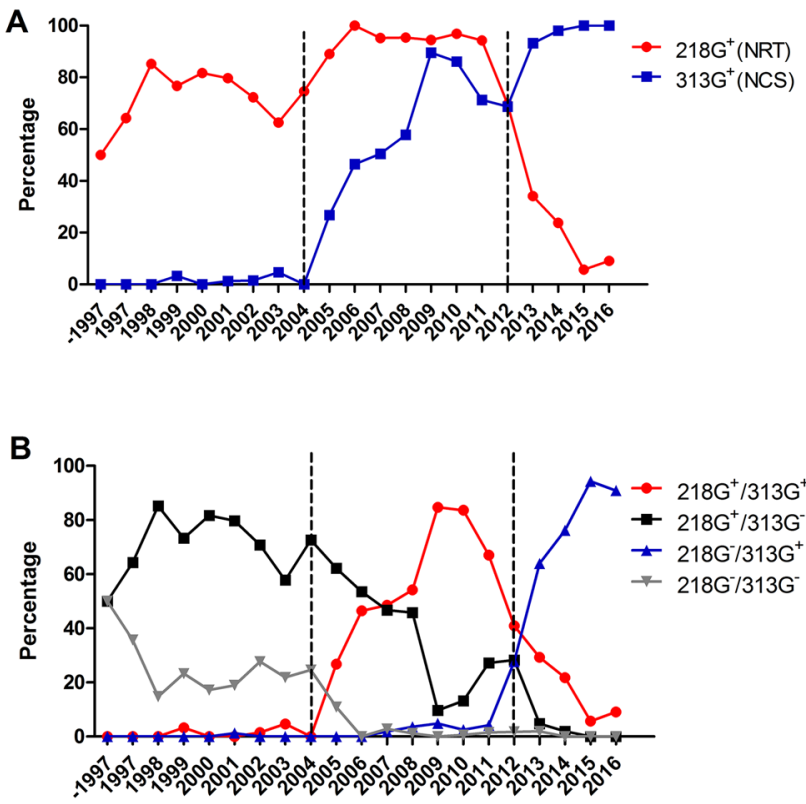

Fig. 1 Analysis of 218 and 313 glycosylation sites in HA gene of H9N2 virus before 2017. About 1900 full-length H9N2 HA amino acid sequences deposited in GenBank from 1997 to 2016 (date to Jan $1,2017)$ in China were analyzed. $218 \mathrm{G}^{+}(\mathrm{NRT})$ indicates Asn-ArgThrat amino acid residues $218-220$, a potential glycosylation site at amino acid residue 218; $313 \mathrm{G}^{+}$(NCS) indicates Asn-Cys-Serat amino acid residues $218-220$, a potential glycosylation site at amino acid residue 218 avian influenza virus isolated in China, deposited in Influenza Virus Resource of NCBI (https://www.ncbi.nlm.nih. gov/genomes/FLU/Database/nph-select.cgi?go=datab ase) before 2017 (date to Jan 1, 2017), were in statistics using DNAstar5.0 software (DNAstar, Madison, WI, USA) (Fig. 1). The proportion of the H9N2 $313 \mathrm{G}^{+}$ viruses annually increased from 2004 to 2009 and have been predominant of more than $93 \%$ since 2013 . The proportion of the $218 \mathrm{G}^{+}$viruses were dominant over more than $89 \%$ from 2005 to 2011 and had decreased to lower than $35 \%$ from 2011 to 2016 , and even lower than $10 \%$ during 2015-2016 (Fig. 1a). Of the variations in NLG sites at amino acids 218 and 313 of H9N2 influenza viruses, the $218 \mathrm{G}^{+} / 313 \mathrm{G}^{-}$viruses were dominant over $50 \%$ before 2007 . The $218 \mathrm{G}^{+} / 313 \mathrm{G}^{+}$viruses were dominant over $40 \%$ from 2008 to 2012 . The $218 \mathrm{G}^{-} / 313 \mathrm{G}^{+}$viruses have been dominant over 63\% from 2013 to 2016. The $218 \mathrm{G}^{-} / 313 \mathrm{G}^{-}$viruses almost have disappeared since 2006 (Fig. 1b).

$\mathrm{F} / 98$ virus is a $218 \mathrm{G}^{+} / 313 \mathrm{G}^{-}$virus. To understand the function of these variations in NGL sites between the amino acids 218 and 313 in the HA of the H9N2 influenza viruses last decade, two reassortant viruses, $\mathrm{rF} /$ $\mathrm{HA} 218 \mathrm{G}^{+} / 313 \mathrm{G}^{+}$and $\mathrm{rF} / \mathrm{HA} 218 \mathrm{G}^{-} / 313 \mathrm{G}^{+}$, were generated based on the $\mathrm{F} 98$ virus backbone. The HA titers of the allantoic fluids of eggs infected with $\mathrm{rF} / \mathrm{HA} 218 \mathrm{G}^{+} / 313 \mathrm{G}^{+}$ and $\mathrm{rF} / \mathrm{HA} 218 \mathrm{G}^{-} / 313 \mathrm{G}^{+}$were 64 and 128 , respectively (Table 1). The results of the HI assay showed that the two reassortant viruses, $\mathrm{rF} / \mathrm{HA} 218 \mathrm{G}^{+} / 313 \mathrm{G}^{+}$and $\mathrm{rF} /$ $\mathrm{HA} 218 \mathrm{G}^{-} / 313 \mathrm{G}^{+}$, viruses only reacted with $\mathrm{F} / 98$ serum, yet did not react with anti-NDV (Newcastle disease virus) and anti-H5 sera (Table 1). The results of the HA sequencing showed that the HA amino acid sequence of the $\mathrm{rF} /$ $\mathrm{HA} 218 \mathrm{G}^{+} / 313 \mathrm{G}^{+}$strain had NCSK at amino acid residues 313-316, indicating a increased NGL site in 313 site, and the $\mathrm{HA}$ amino acid sequence of the $\mathrm{rF} / \mathrm{HA} 218 \mathrm{G}^{-} / 313 \mathrm{G}^{+}$ strain had VRTF at amino acid residues 218-221 and NCSK at amino acid residues 313-316, indicating a decreased NGL site in 218 site, and a increased NGL site in 313 site, respectively.

Table 1 The HA titers and infectivity of viruses in SPF chicken eggs, cells, and the tissue of chickens

\begin{tabular}{|c|c|c|c|c|c|c|c|c|c|c|}
\hline \multirow[t]{2}{*}{ Virus } & \multirow[t]{2}{*}{ HA titers } & \multicolumn{3}{|c|}{ HI titers } & \multirow[t]{2}{*}{$\mathrm{EID}_{50} / 0.2 \mathrm{~mL}$} & \multirow[t]{2}{*}{$\mathrm{TCID}_{50} / 0.2 \mathrm{~mL}$} & \multicolumn{2}{|c|}{$\begin{array}{l}\text { Trachea }^{\mathrm{a}} \\
\left(\mathrm{EID}_{50} / 0.2 \mathrm{~mL}\right)\end{array}$} & \multicolumn{2}{|c|}{$\begin{array}{l}\text { Lung }^{\mathrm{a}} \\
\left(\mathrm{EID}_{50} / 0.2 \mathrm{~mL}\right)\end{array}$} \\
\hline & & NDV & H5 & $\mathrm{F} / 98$ & & & 3 days & 5 days & 3 days & 5 days \\
\hline $\mathrm{F} / 98$ & 2048 & 0 & 0 & 2560 & $10^{-6.67}$ & $10^{-3.67}$ & $10^{-3.5}$ & $10^{-2.25}$ & $10^{-2.25}$ & $10^{-1.75}$ \\
\hline $\mathrm{rF} / \mathrm{HA} 218 \mathrm{G}^{+} / 313 \mathrm{G}^{+}$ & 256 & 0 & 0 & 2560 & $10^{-7.5^{*}}$ & $10^{-4.52^{*}}$ & $10^{-4.25 *}$ & $10^{-2.75}$ & $10^{-2.75}$ & $10^{-2.25^{*}}$ \\
\hline $\mathrm{rF} / \mathrm{HA} 218 \mathrm{G}^{-} / 313 \mathrm{G}^{+}$ & 256 & 0 & 0 & 2560 & $10^{-6.75 \#}$ & $10^{-3.75 \#}$ & $10^{-3.75 \#}$ & $10^{-2.5}$ & $10^{-2.25}$ & $10^{-1.75 \#}$ \\
\hline
\end{tabular}

*Indicates that there is a significant difference between infectivity of $\mathrm{rF} / \mathrm{HA} 218 \mathrm{G}^{+} / 313 \mathrm{G}^{+}$and $\mathrm{F} / 98$ strain in chicken embryo and cell

${ }^{\#}$ Indicates that there is a significant difference between infectivity of $\mathrm{rF} / \mathrm{HA} 218 \mathrm{G}^{+} / 313 \mathrm{G}^{+}$and $\mathrm{rF} / \mathrm{HA}_{2} 18 \mathrm{G}^{-} / 313 \mathrm{G}^{+}$in chicken embryo and cell

${ }^{a}$ Virus mean titer in tracheae or lungs from three SPF chicken infected with each virus 


\section{The effect of variations in the glycosylation sites at amino acid residues 313 and 218 on the mobility of HA protein}

To determine whether amino acid residues 313 and 218 were functional NGL sites, the mobilities of HA proteins of the $\mathrm{rF} / \mathrm{HA} 218 \mathrm{G}^{+} / 313 \mathrm{G}^{+}, \mathrm{rF} / \mathrm{HA} 218 \mathrm{G}^{-} / 313 \mathrm{G}^{+}$, and F/98 strains were compared by western blotting. The results showed that the migration of HA protein of the $\mathrm{rF} /$ $\mathrm{HA} 218 \mathrm{G}^{+} / 313 \mathrm{G}^{+}$strain was significantly slower compared to the F/98 strain, whereas the migration of HA protein of the $\mathrm{rF} / \mathrm{HA} 218 \mathrm{G}^{-} / 313 \mathrm{G}^{+}$strain was faster than that of the $\mathrm{F} / 98$ strain but slower than that of the $\mathrm{rF} / \mathrm{HA} 218 \mathrm{G}^{+} / 313 \mathrm{G}^{+}$ strain, indicating that the NGL sites at amino acid residues 218 and 313 of HA protein are functional glycosylation sites (Fig. 2) [21]. And the quantitative analysis of $\mathrm{rF} /$ HA2 $18 \mathrm{G}^{+} / 313 \mathrm{G}^{+}$virus, $\mathrm{rF} / \mathrm{HA} 218 \mathrm{G}^{-} / 313 \mathrm{G}^{+}$virus, and $\mathrm{F} / 98$ virus on movement were $11307.447,16895.861$, and 17919.811, respectively, using ImageJ program.

\section{Variations in glycosylation sites at amino acid residues 313 and 218 physically in HA affect the antigenicity of H9N2 influenza virus}

To address if the variations in glycosylation sites at amino acid residues 313 and 218 in HA affect the antigenicity of H9N2 influenza virus, the antibody binding ELISAs were performed. Compared to the $\mathrm{F} / 98$ virus, the titer of the $\mathrm{rF} /$ $\mathrm{HA} 218 \mathrm{G}^{-} / 313 \mathrm{G}^{+}$virus binding to the sera of the $\mathrm{F} / 98$ virus was significantly stronger than the $\mathrm{rF} / \mathrm{HA} 218 \mathrm{G}^{+} / 313 \mathrm{G}^{+}$ virus, and the F/98 virus at the $10^{-7}$ diluent sera of the F/98 virus (Fig. 3), indicating that $313 \mathrm{G}^{+}$with $218 \mathrm{G}^{-}$could increase the binding ability of the $\mathrm{rF} / \mathrm{HA} 218 \mathrm{G}^{-} / 313 \mathrm{G}^{+}$virus to the sera of the parental F/98, and affect the antigenicity of H9N2 influenza virus.

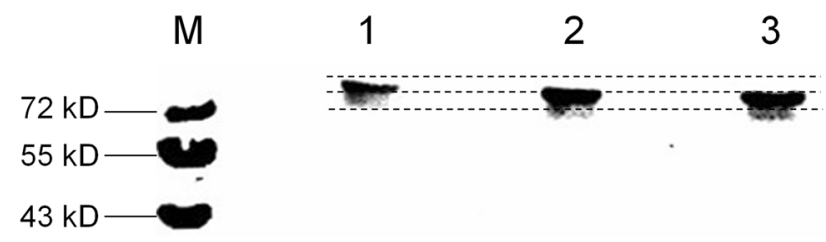

Fig. 2 Western blot analysis of $\mathrm{F} / 98, \mathrm{rF} / \mathrm{HA} 218 \mathrm{G}^{+} / 313 \mathrm{G}^{+}$, and $\mathrm{rF} /$ $\mathrm{HA} 218 \mathrm{G}^{-} / 313 \mathrm{G}^{+}$viruses. The purified $\mathrm{H} 9 \mathrm{~N} 2$ viruses were incubated with chicken anti-F/98 antiserum. Binding was visualized with a chemiluminescent substrate using the kit ECL Plus Western Blotting System according to manufacturer's instructions. Locations of marker proteins were indicated on the left, and the HA of AIV are indicated on the right. M: Protein Marker; $1: \mathrm{rF} / \mathrm{HA} 218 \mathrm{G}^{+} / 313 \mathrm{G}^{+}$virus; $2: \mathrm{rF} /$ $\mathrm{HA}_{2} 18 \mathrm{G}^{-} / 313 \mathrm{G}^{+}$virus; 3 : $\mathrm{F} / 98$ virus. The quantitative analyses of $\mathrm{rF} / \mathrm{HA} 218 \mathrm{G}^{+} / 313 \mathrm{G}^{+}$virus, $\mathrm{rF} / \mathrm{HA} 218 \mathrm{G}^{-} / 313 \mathrm{G}^{+}$virus, and $\mathrm{F} / 98$ virus on movement were $11307.447,16895.861$, and 17919.811, respectively, using ImageJ program

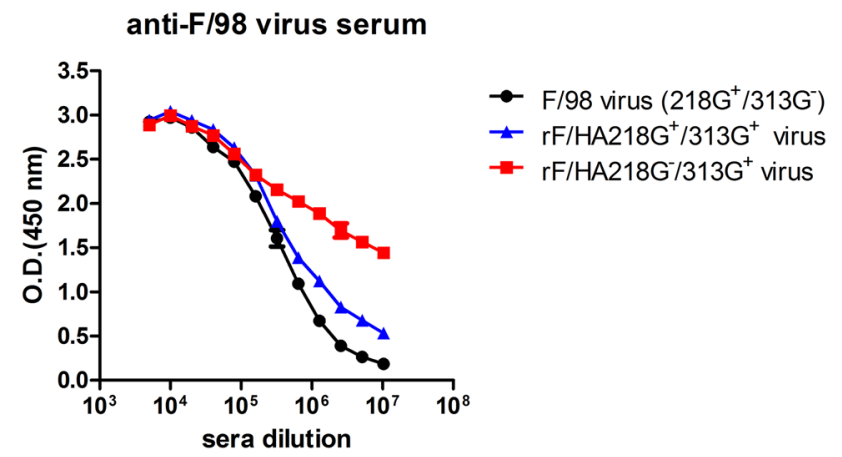

Fig. 3 Variations in the glycosylation sites at amino acid residues 313 and 218 physically lead to antibody binding change. Antibody binding to different viruses was determined by ELISA using sera isolated from chickens infected with the F/98 virus possessing the glycosylation sites at amino acid residues 313. Means and SEM from triplicate samples are shown. The data are representative of three independent experiments. O.D., absorbance, recorded at $450 \mathrm{~nm}$. *Indicated $p<0.05$

\section{The effect of variations in glycosylation sites at amino acid residues 313 and 218 on the biological characteristics of the H9N2 virus}

To study the effect of HA glycosylation sites on the biological characteristics of the H9N2 virus, such as the $50 \%$ egg infectious dose $\left(\mathrm{EID}_{50}\right), 50 \%$ egg lethal dose $\left(\mathrm{ELD}_{50}\right)$, and $50 \%$ tissue cell infectious dose $\left(\mathrm{TCID}_{50}\right)$, pathogenicity in chickens and mice, transmission route, and antigenic variation of the H9N2 virus in chickens were analyzed. Compared to the F/98 strain, the $\mathrm{EID}_{50}$ and $\mathrm{TCID}_{50}$ of the $\mathrm{rF} / \mathrm{HA} 218 \mathrm{G}^{+} / 313 \mathrm{G}^{+}$strain was significantly increased by 6.76 -fold, and 7.07-fold, respectively. Conversely, the EID $_{50}$ and TCID $_{50}$ of the $\mathrm{rF} / \mathrm{HA} 218 \mathrm{G}^{-} / 313 \mathrm{G}^{+}$strain had similar titers but were significantly decreased by 5.62 fold, and 6.02-fold, respectively, relative to the $\mathrm{EID}_{50}$ and TCID $_{50}$ of the $\mathrm{rF} / \mathrm{HA} 218 \mathrm{G}^{+} / 313 \mathrm{G}^{+}$strain (Table 1 ). At days 3 and 5 post-infection, the EID $_{50}$ titers of the $\mathrm{rF} /$ $\mathrm{HA} 218 \mathrm{G}^{+} / 313 \mathrm{G}^{+}$strain in chicken tissue were significantly higher by 5.62 -fold and 3.16-fold in the trachea and decreased by 3.16 -fold and 3.16-fold in the lung compared to the $\mathrm{F} / 98$ strain. However, the infectious doses of the $\mathrm{rF} /$ HA218G- $/ 313 \mathrm{G}^{+}$strain were decreased by 3.16 -fold and 1.78 -fold in the trachea and decreased by 3.16 -fold and 3.16 -fold in the lung compared to the $\mathrm{rF} / \mathrm{HA} 218 \mathrm{G}^{+} / 313 \mathrm{G}^{+}$ strain; however, there were no significant differences of EID $_{50}$ and TCID $_{50}$ in either the trachea or lung, compared to the F/98 strain (Table 1).

In mice, no clinical characteristics were observed, and none of the viral strains were detected in the lung at days 3 and 5 post-infection, which is also characteristic of the F/98 strain in mice. However, the discomfort, the mild diarrhea, and the mucus in the sinuses of the chickens 
infected with the viral strains were observed at days 3 post-infection, and then disappeared in the next several days.

Animal transmission experiments showed that the F/98, $\mathrm{rF} / \mathrm{HA} 218 \mathrm{G}^{+} / 313 \mathrm{G}^{+}$, and $\mathrm{rF} / \mathrm{HA} 218 \mathrm{G}^{-} / 313 \mathrm{G}^{+}$strains could be spread by direct contact and airborne contact, indicating that the variations in the glycosylation sites at amino acid residues 313 and 218 had no effect on the transmission routes of the virus (Table 2).

In the immunogenic test, it was found that the antibody (HI:128-512) induced by the F/98 vaccine could provide $100 \%$ protection against the challenge by both the $\mathrm{rF} /$ $\mathrm{HA} 218 \mathrm{G}^{+} / 313 \mathrm{G}^{+}$and $\mathrm{rF} / \mathrm{HA} 218 \mathrm{G}^{-} / 313 \mathrm{G}^{+}$strains since no shedding was detected in the groups challenged with those strains. This result indicated that the variations in glycosylation sites at amino acid residues 313 and 218 did not result in the antigenic variation of the F/98 strain. In the control group, all chickens immunized with PBS exhibited viral shedding in the trachea or cloaca with 0 HI titer (Table 3).

\section{Discussions}

Normally $\mathrm{N}$-linked glycosylation involves a class of amino acid constructs with N-X-S/T-X [28]. Changes in certain glycosylation sites of the viral proteins may have a significant effect on the biological characteristics of the virus [29-31], such as virulence, and the function of the affected viral proteins. Studies have shown that changes in the glycosylation status near HA protein cleavage site may affect the virulence of the virus [7]. Changes of the glycosylation status in the antigenic region of HA protein of the influenza virus may affect the binding of the virus to the antibody to generate the mutants in HA [6, 32], while changes of the glycosylation at some positions have no effect on the structure and function of the virus.

Based on variations in glycosylation sites at amino acid residues 313 and 218, the evolution of H9N2 avian influenza viruses are divided into three categories: 1997-2004, 2005-2012, and 2013-2016. During these categories, variations in the glycosylation sites at amino acid residues 313

Table 2 Results of viruses isolated from tracheal and cloacal swabs from 3 to 9 days. Three chickens were included in each way of infection with each virus

\begin{tabular}{|c|c|c|c|c|c|c|c|c|c|}
\hline \multirow[t]{3}{*}{ Virus } & \multirow[t]{3}{*}{ Ways of infection } & \multicolumn{8}{|c|}{ Positive/total $^{\mathrm{a}}$} \\
\hline & & \multicolumn{4}{|c|}{ Tracheal swabs } & \multicolumn{4}{|c|}{ Cloacal swabs } \\
\hline & & 3 days & 5 days & 7 days & 9 days & 3 days & 5 days & 7 days & 9 days \\
\hline \multirow[t]{3}{*}{$\mathrm{F} / 98\left(\mathrm{HA} 218 \mathrm{G}^{+} / 313 \mathrm{G}^{-}\right)$} & Directly inoculation & $3 / 3$ & $2 / 3$ & $0 / 3$ & $0 / 3$ & $2 / 3$ & $2 / 3$ & $0 / 3$ & $0 / 3$ \\
\hline & Directly contact & $2 / 3$ & $2 / 3$ & $0 / 3$ & $0 / 3$ & $0 / 3$ & $1 / 3$ & $0 / 3$ & $0 / 3$ \\
\hline & Airborne contact & $0 / 3$ & $2 / 3$ & $1 / 3$ & $0 / 3$ & $0 / 3$ & $0 / 3$ & $0 / 3$ & $0 / 3$ \\
\hline \multirow[t]{3}{*}{$\mathrm{rF} / \mathrm{HA} 218 \mathrm{G}^{+} / 313 \mathrm{G}^{+}$} & Directly inoculation & $3 / 3$ & $3 / 3$ & $2 / 3$ & $0 / 3$ & $2 / 3$ & $2 / 3$ & $0 / 3$ & $0 / 3$ \\
\hline & Directly contact & $2 / 3$ & $2 / 3$ & $1 / 3$ & $0 / 3$ & $0 / 3$ & $1 / 3$ & $0 / 3$ & $0 / 3$ \\
\hline & Airborne contact & $0 / 3$ & $2 / 3$ & $1 / 3$ & $0 / 3$ & $0 / 3$ & $0 / 3$ & $0 / 3$ & $0 / 3$ \\
\hline \multirow[t]{3}{*}{$\mathrm{rF} / \mathrm{HA} 218 \mathrm{G}^{-} / 313 \mathrm{G}^{+}$} & Directly inoculation & $3 / 3$ & $2 / 3$ & $1 / 3$ & $0 / 3$ & $2 / 3$ & $2 / 3$ & $1 / 3$ & $0 / 3$ \\
\hline & Directly contact & $1 / 3$ & $2 / 3$ & $1 / 3$ & $0 / 3$ & $0 / 3$ & $1 / 3$ & $1 / 3$ & $0 / 3$ \\
\hline & Airborne contact & $0 / 3$ & $1 / 3$ & $1 / 3$ & $0 / 3$ & $0 / 3$ & $0 / 3$ & $0 / 3$ & $0 / 3$ \\
\hline
\end{tabular}

${ }^{a}$ Number of positive tracheal or cloacal/total number of chickens. Positive sample indicated higher than the detection limit of $2^{2} \mathrm{HA}$ titer

Table 3 Isolation of $\mathrm{H} 9 \mathrm{~N} 2$ viruses in vaccinated chickens after challenged with $\mathrm{PBS}, \mathrm{F} / 98, \mathrm{rF} / \mathrm{HA} 218 \mathrm{G}^{+} / 313 \mathrm{G}^{+}$, and $\mathrm{rF} / \mathrm{HA}^{2} 18 \mathrm{G}^{-} / 313 \mathrm{G}^{+}$ viruses at 3 and 5 days

\begin{tabular}{|c|c|c|c|c|}
\hline \multirow[t]{3}{*}{ Groups } & \multicolumn{4}{|c|}{ Positive/total $^{\mathrm{a}}$} \\
\hline & \multicolumn{2}{|c|}{ Tracheal swabs } & \multicolumn{2}{|c|}{ Cloacal swabs } \\
\hline & 3 dpi & 5 dpi & 3 dpi & 5 dpi \\
\hline SPF chickens inoculated F/98 strain virus after immunized with PBS & $3 / 3$ & $2 / 3$ & $2 / 3$ & $2 / 3$ \\
\hline SPF chickens inoculated F/98 strain virus after immunized with F/98 vaccine & $0 / 3$ & $0 / 3$ & $0 / 3$ & $0 / 3$ \\
\hline SPF chickens inoculated $\mathrm{rF} / \mathrm{HA} 218 \mathrm{G}^{+} / 313 \mathrm{G}^{+}$virus after immunized with $\mathrm{F} / 98$ vaccine & $0 / 3$ & $0 / 3$ & $0 / 3$ & $0 / 3$ \\
\hline SPF chickens inoculated $\mathrm{rF} / \mathrm{HA} 218 \mathrm{G}^{-} / 313 \mathrm{G}^{+}$virus after immunized with $\mathrm{F} / 98$ vaccine & $0 / 3$ & $0 / 3$ & $0 / 3$ & $0 / 3$ \\
\hline
\end{tabular}

Three chickens were included in each experiment group

${ }^{a}$ Number of positive tracheal or cloacal/total number of chickens. Positive sample indicated higher than the detection limit of $2^{2}$ HA titer 
and 218 were dynamic. In last decade, the proportion of the $218 \mathrm{G}^{+} / 313 \mathrm{G}^{+}$viruses and the $218 \mathrm{G}^{-} / 313 \mathrm{G}^{+}$viruses were predominant during 2008-2012, 2013-2016, respectively. These changes occur through the process of viral evolution. Based on the viruses from the latest two categories (from 2008 to 2012, and from 2013 to 2016), two F/98original reassortment viruses, $\mathrm{rF} / \mathrm{HA} 218 \mathrm{G}^{+} / 313 \mathrm{G}^{+}$and $\mathrm{rF} /$ $\mathrm{HA} 218 \mathrm{G}^{-} / 313 \mathrm{G}^{+}$, were generated. A functional glycosylation site in HA protein could affect on the mobility of HA protein on the gel [21]. The mobility analysis of HA proteins showed that the two potential glycosylation sites at amino acid residues 313 and 218 in HA protein are both functional glycosylation sites. The F/98 virus possesses a functional glycosylation site at amino acid residue 218 . The $\mathrm{rF} / \mathrm{HA} 218 \mathrm{G}^{+} / 313 \mathrm{G}^{+}$virus possesses two functional glycosylation sites at amino acid residues 218 and 313. The $\mathrm{rF} /$ HA218G $\mathrm{G}^{-} / 313 \mathrm{G}^{+}$virus possesses a functional glycosylation site at amino acid residue 313. And our result showed that the $\mathrm{rF} / \mathrm{HA} 218 \mathrm{G}^{-} / 313 \mathrm{G}^{+}$viruses could bind to the antibody of the parental virus F/98 more efficiently than the viruses $\mathrm{F} / 98$, indicating that the $\mathrm{rF} / \mathrm{HA} 218 \mathrm{G}^{+} / 313 \mathrm{G}^{+}$virus or the $\mathrm{rF} /$ HA2 $18 \mathrm{G}^{-} / 313 \mathrm{G}^{+}$virus could enhance antibody responses by increasing virus-antibody binding, or may compensate for the other mutants occurred in HA to maintain fitness during the evolution of H9N2 virus. NLG compensates for antibody escape fitness costs of antigenic escape mutations via a detrimental loss of binding avidity, which prevent binding of virus to host cells [15]. The antigenic profile of each virus is determined through $\mathrm{HI}$ assay using reference sera, and two factors could affect the HI titer, the receptor binding avidity, and antibody binding [22]. In this study, the receptor binding was free from variations in glycosylation sites at amino acid residues 313 and 218 (no date was shown). Additionally, our research team and other researchers find that the antibody selective pressure derived from vaccine affect the evolution of influenza virus, including variation of glycosylation sites $[15,33]$, and the time of changes on glycosylation sites at hemagglutinin amino acid 218 and 313 was similar to the time of changes on some antigenically sites on HA [34]. We hypothesize that the variations in the glycosylation sites at amino acid residues 313 and 218, which enhanced antibody responses by increasing virus-antibody binding, maybe reveal novel viral adaptive mechanisms. Furthermore, our results seem to demonstrate that changes on variations in glycosylation sites at amino acid residues 218 and 313 are associated with the viral antigenicity evolution. Additionally, growth of viruses lacking glycosylation at either $158 \mathrm{~N}$ or $169 \mathrm{~N}$ of the H5N1 avian influenza virus was significantly reduced both in MDCK and A549 cells, while replication of viruses with additional glycosylation $144 \mathrm{~N}$ of H5N1 virus was significantly promoted, and mutant viruses with loss of $158 \mathrm{~N}$ or $169 \mathrm{~N}$ glycosylation sites showed increased pathogenicity in mice [24]. However, in our results, either the $\mathrm{rF} /$
$\mathrm{HA} 218 \mathrm{G}^{+} / 313 \mathrm{G}^{+}$virus or the $\mathrm{rF} / \mathrm{HA} 218 \mathrm{G}^{-} / 313 \mathrm{G}^{+}$virus significantly increased infectivity of MDCK cells, chicken embryo eggs, and trachea and lung tissue in SPF chickens compared with F/98 virus, but they did not change the characteristics of the airborne spread in chickens or of infectivity of mice.

In conclusion, by analyzing and comparing the changes of glycosylation sites of the HA protein sequences in the H9N2 avian influenza viruses before 2017, we designed and generated two viruses, $\mathrm{rF} / \mathrm{HA} 218 \mathrm{G}^{+} / 313 \mathrm{G}^{+}$virus and $\mathrm{rF} / \mathrm{HA} 218 \mathrm{G}^{-} / 313 \mathrm{G}^{+}$, based on the $\mathrm{F} / 98$ virus backbone, a $218 \mathrm{G}^{+} / 313 \mathrm{G}^{-} \mathrm{H} 9 \mathrm{~N} 2$ avian influenza virus. In comparison with original $\mathrm{F} / 98$ virus, the variations in the glycosylation sites at amino acid residues 313 and 218 near the HA cleavage site increased antibody binding and significantly affected the viral infectivity of cells, chicken embryo eggs, or SPF chickens, but those changes did not affect the property of the airborne propagation, or infectivity of mice.

Acknowledgements This work was supported by the National Natural Science Foundation of China (31672516, 31172300, 30670079), supported by the Grant No. BE2016343 from Jiangsu province, the Jiangsu University and College Natural Science Foundation (12KJA230002), the Doctoral Program of Higher Education of China (20133250110002), and a project funded by the Priority Academic Program Development of Jiangsu Higher Education Institutions (PAPD).

Author contributions QQP performed the main experiments and edited the paper; RZ was involved in executing the study and editing the paper; HYS and SFW participated in experimental design; XBW, $\mathrm{MB}$, and XFL revised the paper.

\section{Compliance with ethical standards}

Conflict of interest The authors declare no conflict of interest.

Ethical approval Procedures involving the care and use of animals were approved by the Jiangsu Administrative Committee for Laboratory Animals (permission number SYXK-SU-2007-0005) and complied with the Jiangsu Laboratory Animal Welfare and Ethics guidelines of the Jiangsu Administrative Committee of Laboratory Animals.

Open Access This article is distributed under the terms of the Creative Commons Attribution 4.0 International License (http://creativeco mmons.org/licenses/by/4.0/), which permits unrestricted use, distribution, and reproduction in any medium, provided you give appropriate credit to the original author(s) and the source, provide a link to the Creative Commons license, and indicate if changes were made.

\section{References}

1. Tate MD, Job ER, Deng YM, Gunalan V, Maurer-Stroh S, Reading PC (2014) Playing hide and seek: how glycosylation of the influenza virus hemagglutinin can modulate the immune response to infection. Viruses 6(3):1294-1316. https://doi.org/10.3390/v6031 294 
2. Kornfeld R, Kornfeld S (1985) Assembly of asparagine-linked oligosaccharides. Annu Rev Biochem 54(1):631-664

3. Xu C, Ng DT (2015) Glycosylation-directed quality control of protein folding. Nat Rev Mol Cell Biol 16(12):742-752. https:// doi.org/10.1038/nrm4073

4. Kim JI, Park MS (2012) N-linked glycosylation in the hemagglutinin of influenza A viruses. Yonsei Med J 53(5):886-893. https ://doi.org/10.3349/ymj.2012.53.5.886

5. Gambaryan AS, Marinina VP, Tuzikov AB, Bovin NV, Rudneva IA, Sinitsyn BV, Shilov AA, Matrosovich MN (1998) Effects of host-dependent glycosylation of hemagglutinin on receptor-binding properties on $\mathrm{H} 1 \mathrm{~N} 1$ human influenza $\mathrm{A}$ virus grown in MDCK cells and in embryonated eggs. Virology 247(2):170-177

6. Aytay S, Schulze IT (1991) Single amino acid substitutions in the hemagglutinin can alter the host range and receptor binding properties of H1 strains of influenza A virus. J Virol 65(6):3022-3028

7. Deshpande KL, Fried VA, Ando M, Webster RG (1987) Glycosylation affects cleavage of an H5N2 influenza virus hemagglutinin and regulates virulence. Proc Natl Acad Sci USA 84(1):36-40

8. Schulze IT (1997) Effects of glycosylation on the properties and functions of influenza virus hemagglutinin. J Infect Dis 176(Suppl 1):S24-S28

9. Skehel JJ, Stevens DJ, Daniels RS, Douglas AR, Knossow M, Wilson IA, Wiley DC (1984) A carbohydrate side chain on hemagglutinins of Hong Kong influenza viruses inhibits recognition by a monoclonal antibody. Proc Natl Acad Sci USA 81(6):1779-1783

10. Vigerust DJ, Shepherd VL (2007) Virus glycosylation: role in virulence and immune interactions. Trends Microbiol 15(5):211218. https://doi.org/10.1016/j.tim.2007.03.003

11. Xu R, Ekiert DC, Krause JC, Hai R, Crowe JE Jr, Wilson IA (2010) Structural basis of preexisting immunity to the $2009 \mathrm{H} 1 \mathrm{~N} 1$ pandemic influenza virus. Science 328(5976):357-360. https:// doi.org/10.1126/science. 1186430

12. Wei CJ, Boyington JC, Dai K, Houser KV, Pearce MB, Kong WP, Yang ZY, Tumpey TM, Nabel GJ (2010) Cross-neutralization of 1918 and 2009 influenza viruses: role of glycans in viral evolution and vaccine design. Sci Transl Med 2(24):24ra21. https://doi. org/10.1126/scitranslmed.3000799

13. Baigent SJ, McCauley JW (2001) Glycosylation of haemagglutinin and stalk-length of neuraminidase combine to regulate the growth of avian influenza viruses in tissue culture. Virus Res 79(1-2):177-185

14. Job ER, Deng YM, Barfod KK, Tate MD, Caldwell N, Reddiex S, Maurer-Stroh S, Brooks AG, Reading PC (2013) Addition of glycosylation to influenza A virus hemagglutinin modulates antibody-mediated recognition of H1N1 2009 pandemic viruses. J Immunol 190(5):2169-2177. https://doi.org/10.4049/jimmu nol.1202433

15. Kosik I, Ince WL, Gentles LE, Oler AJ, Kosikova M, Angel M, Magadan JG, Xie H, Brooke CB, Yewdell JW (2018) Influenza A virus hemagglutinin glycosylation compensates for antibody escape fitness costs. PLoS Pathog 14(1):e1006796. https://doi. org/10.1371/journal.ppat.1006796

16. Klenk HD, Wagner R, Heuer D, Wolff T (2002) Importance of hemagglutinin glycosylation for the biological functions of influenza virus. Virus Res 82(1-2):73-75

17. Lu JH, Liu XF, Shao WX, Liu YL, Wei DP, Liu HQ (2005) Phylogenetic analysis of eight genes of H9N2 subtype influenza virus: a mainland China strain possessing early isolates' genes that have been circulating. Virus Genes 31(2):163-169. https:// doi.org/10.1007/s11262-005-1790-1

18. Shi H, Ashraf S, Gao S, Lu J, Liu X (2010) Evaluation of transmission route and replication efficiency of $\mathrm{H} 9 \mathrm{~N} 2$ avian influenza virus. Avian Dis 54(1):22-27. https://doi.org/10.1637/8937-05280 9-Reg.1

19. Hoffmann E, Neumann G, Kawaoka Y, Hobom G, Webster RG (2000) A DNA transfection system for generation of influenza A virus from eight plasmids. Proc Natl Acad Sci USA 97(11):61086113. https://doi.org/10.1073/pnas.100133697

20. EXPERT Committee on Influenza, first report (1953) World Health Organ Tech Rep Ser 6(64):1-32

21. Ping J, Li C, Deng G, Jiang Y, Tian G, Zhang S, Bu Z, Chen H (2008) Single-amino-acid mutation in the HA alters the recognition of H9N2 influenza virus by a monoclonal antibody. Biochem Biophys Res Commun 371(1):168-171. https://doi.org/10.1016/j. bbrc.2008.04.045

22. Li Y, Bostick DL, Sullivan CB, Myers JL, Griesemer SB, Stgeorge K, Plotkin JB, Hensley SE (2013) Single hemagglutinin mutations that alter both antigenicity and receptor binding avidity influence influenza virus antigenic clustering. J Virol 87(17):9904-9910. https://doi.org/10.1128/JVI.01023-13

23. Reed LJ, Muench H (1938) A simple method of estimating fifty percent endpoints. Am J Hyg 27:493-497

24. Zhang X, Chen S, Jiang Y, Huang K, Huang J, Yang D, Zhu J, Zhu Y, Shi S, Peng D, Liu X (2015) Hemagglutinin glycosylation modulates the pathogenicity and antigenicity of the H5N1 avian influenza virus. Vet Microbiol 175(2-4):244-256. https:// doi.org/10.1016/j.vetmic.2014.12.011

25. Shi H, Liu XF, Zhang X, Chen S, Sun L, Lu J (2007) Generation of an attenuated $\mathrm{H} 5 \mathrm{~N} 1$ avian influenza virus vaccine with all eight genes from avian viruses. Vaccine 25(42):7379-7384. https://doi. org/10.1016/j.vaccine.2007.08.011

26. Steel J, Lowen AC, Mubareka S, Palese P (2009) Transmission of influenza virus in a mammalian host is increased by PB2 amino acids $627 \mathrm{~K}$ or 627E/701N. PLoS Pathog 5(1):e1000252. https:// doi.org/10.1371/journal.ppat.1000252

27. Hatta M, Gao P, Halfmann P, Kawaoka Y (2001) Molecular basis for high virulence of Hong Kong H5N1 influenza A viruses. Science 293(5536):1840-1842. https://doi.org/10.1126/scien ce. 1062882

28. Marshall RD (1974) The nature and metabolism of the carbohydrate-peptide linkages of glycoproteins. Biochem Soc Symp 40:17-26

29. Hebert DN, Zhang JX, Chen W, Foellmer B, Helenius A (1997) The number and location of glycans on influenza hemagglutinin determine folding and association with calnexin and calreticulin. J Cell Biol 139(3):613-623

30. Land A, Braakman I (2001) Folding of the human immunodeficiency virus type 1 envelope glycoprotein in the endoplasmic reticulum. Biochimie 83(8):783-790

31. Slater EE (2004) Industry and government perspective in influenza control. Tex Heart Inst J 31(1):42-44

32. Gallagher P, Henneberry J, Wilson I, Sambrook J, Gething MJ (1988) Addition of carbohydrate side chains at novel sites on influenza virus hemagglutinin can modulate the folding, transport, and activity of the molecule. J Cell Biol 107(6 Pt 1):2059-2073

33. Jin H, Wang W, Yang X, Su H, Fan J, Zhu R, Wang S, Shi H, Liu $X$ (2018) Evolution of H9N2 avian influenza virus in embryonated chicken eggs with or without homologous vaccine antibodies. BMC Vet Res 14(1):71. https://doi.org/10.1186/s1291 7-018-1391-6

34. Zhu R, Xu D, Yang X, Zhang J, Wang S, Shi H, Liu X (2018) Genetic and biological characterization of H9N2 avian influenza viruses isolated in China from 2011 to 2014. PLoS ONE 13(7):e0199260. https://doi.org/10.1371/journal.pone.0199260

Publisher's Note Springer Nature remains neutral with regard to jurisdictional claims in published maps and institutional affiliations. 